\title{
Quality Management System in a Haemodialysis Unit and Patient Satisfaction
}

\author{
Athanasia Kavalieratou ${ }^{1 *}$, Georgia Garofyllou ${ }^{2}$, Eftychia Evangelidou ${ }^{1}$, \\ Michalis Mantzanas ${ }^{1}$ \\ ${ }^{l}$ General Hospital N. Ionias Konstantopouleio-Patision, Department of Nursing Management, 14233, Athens, Greece. \\ ${ }^{2}$ General Hospital N. Ionias Konstantopouleio-Patision, Haemodialysis Unit, 14233, Athens, Greece.
}

Received 06 March 2021; Revised 22 May 2021; Accepted 19 June 2021; Published 01 September 2021

\begin{abstract}
Haemodialysis Units adopt a Quality Management System to provide quality healthcare services, to promote reliability and to increase the patients' contentment and faith they receive the best possible care. The purpose of this study was to ascertain whether the ELOT EN ISO 9001:2015 Quality Management System, "Provision of Dialysis Services in Patients with Renal Failure", in a Haemodialysis Unit affected the patients' satisfaction level. The Quality Management System stipulated the use of a questionnaire containing 11 questions to measure the patients' satisfaction. The data were collected in July 2018 during the annual audit for the continuous compliance of the Haemodialysis Unit with the quality requirements. 35 patients undergoing Chronic Haemodialysis for at least the last 6 months participated. The Quality Management System enabled the identification of the patients' individual needs and the areas that required more attention. More specifically, $97.1 \%$ of the patients stated that the services provided had been improved and that requests such as the installation of TVs and the collaboration with a dietologist have been met. $77.1 \%$ of the patients were satisfied by the healthcare provided and $88.6 \%$ were satisfied by the staff in general. Regarding the care provided by the medical staff $74.3 \%$ of the patients were satisfied, while $54.2 \%$ found the information given for their health to be adequate. All of the patients $(100 \%)$ were satisfied by the care provided by the nursing staff and almost all $(97.1 \%)$ felt that the nursing staff was easy to communicate with. Only $6.1 \%$ of the patients stated that specific areas required further improvement. A Quality Management System in a Haemodialysis Unit leads to a better understanding of the patients' individual needs, allowing for higher satisfaction. Moreover, the evidence based documentation of the quality of the services provided and the emphasis put on continuous improvement further enhances the patients' trust.
\end{abstract}

Keywords: Haemodialysis; Haemodialysis Unit; Patient Satisfaction; Quality Management System.

\section{Introduction}

The incidence of end stage renal disease (ESRD) is increasing worldwide [1] and it should be noted that on a global level the number of the individuals who are estimated to suffer from kidney disease surpasses 850 million people [2]. More specifically, the global data for the years 1990-2016 regarding the incidence and prevalence of chronic kidney disease show that during that time there has been an increase by 89 and $87 \%$, respectively, which subsequently leads to an increase of the number of patients undergoing chronic haemodialysis [3].

* Corresponding author: siakav@yahoo.com

dol http://dx.doi.org/10.28991/SciMedJ-2021-0303-2

$>$ This is an open access article under the CC-BY license (https://creativecommons.org/licenses/by/4.0/).

(C) Authors retain all copyrights. 
The patients undergoing chronic haemodialysis experience restrictions regarding their diet, social life and occupation [4], as well as fatigue, anxiety and sleep disorders which severely impair their quality of life [1, 5, 6]. Since these patients are facing a chronic illness the evaluation of the adequacy of the dialysis treatment should not be focused solely on clinical outcomes and ultimately on the patients' survival, but also on the improvement of the quality of their life [1,7]. The quality of life of patients undergoing chronic haemodialysis is affected among other things by the quality of the health services provided and the level of fulfillment of the patients' personal preferences and their satisfaction [8, 9]. The patients' satisfaction moreover, can be perceived as the level of balance between the patient's expectations as to the results of the provided healthcare and the perception of the healthcare they receive in reality $[10]$.

Nowadays, Haemodialysis Units increasingly adopt a Quality Management System (QMS) which can be successfully applied to renal care, in order to ensure the provision of healthcare services that meet high standards of quality [11]. The implementation of a QMS is a strategic decision to promote effectiveness, reliability and safety in a Haemodialysis Unit, but also to increase the patients' contentment and faith that they receive the best possible care, as it organizes the coordination and control of all activities, while it allows the reduction of operational costs [12, 13].

\subsection{Purpose}

The purpose of this study was to ascertain whether the implementation of the ELOT EN ISO 9001:2015 Quality Management System, for the "Provision of Dialysis Services in Patients with Renal Failure", in a Haemodialysis Unit affected the patients' level of trust and satisfaction.

\section{Research Methodology}

The QMS specified directives for all services of the Haemodialysis Unit and all processes were categorized in GPs which composed the Quality Manual. Among the procedures regulated was the Control of the patients' suggestions and complaints (GP.HU.150), which made use of a questionnaire composed of 11 questions to evaluate the patients' trust and satisfaction regarding the healthcare provided. The first 9 questions had a grading scale that ranged from "High" to "Not at all" regarding the satisfaction levels, while the last two asked the patients about their belief whether further improvements were necessary and about their suggestions/complaints. A structured interview was conducted according to the stipulations of the Annual audit and review, performed to ensure the continuous compliance of the Haemodialysis Unit with the quality requirements. The data were collected in June 2018 with the participation of 35 patients undergoing Chronic Haemodialysis at the Haemodialysis Unit. Subsequently the data was statistically analyzed descriptively, using frequency measures, according to the Annual audit requirements.

The inclusion criteria were:

- Diagnosis of ESRD;

- Receiving dialysis treatment at the specific haemodialysis unit for at least 6 months;

- Age over 18 years;

- Ability to speak and understand the Greek language;

- Absence of any psychiatric disease.

\section{Results}

The implementation of the QMS required the creation of a Quality Manual which consisted of 5 Sections and specified directives for all services of the Haemodialysis Unit (HU), while all processes were regulated in General Procedures (GPs). The General Procedures of the HU can be seen in detail in Table 1.

Also, a Process Interrelationship Chart that demonstrates the relation of all GPs of the Quality Management System to one another can be seen on Figure 1.

After the initial establishment of the QMS, the successful implementation of its directives is ascertained by the achievement of certain Objectives that have been established according to the Quality Policy [11, 13]. These Objectives are in accordance to the official best practices in the field of renal care and can be measured by specific Quality Indicators [14]. The Quality Indicators used, reflect all aspects of the healthcare provided; they are evidencebased and are measured objectively, by a specifically set time table [14]. They can be grouped in 11 general categories, which are shown in Table 2. Moreover, the Haemodialysis Unit is subject to periodic reviews whenever it is deemed necessary and to an Annual Audit by an external inspector to ensure the continuous compliance with the quality requirements, in order to prove the quality of the services provided and to maintain its accreditation. 
Table 1. General Procedures of the Haemodialysis Unit

\begin{tabular}{|c|c|c|}
\hline SECTION 1 & General Procedures & Processes \\
\hline \multirow{5}{*}{ QUALITY MANAGEMENT } & GP.HU.110 & Control of documents and records of the QMS \\
\hline & GP.HU.120 & Periodic review and Annual audit of the QMS \\
\hline & GP.HU.130 & Control of Quality Indicators and statistical data \\
\hline & GP.HU.140 & $\begin{array}{l}\text { Management of non-conforming incidents, corrective and preventive } \\
\text { actions }\end{array}$ \\
\hline & GP.HU.150 & Control of clients' suggestions and complaints \\
\hline SECTION 2 & General Procedures & Processes \\
\hline HUMAN RESOURCES & GP.HU.210 & Human Resources Management \\
\hline SECTION 3 & General Procedures & Processes \\
\hline SUPPLIES & GP.HU.310 & Procurement and control of product supplies \\
\hline SECTION 4 & General Procedures & Processes \\
\hline EQUIPMENT AND ENVIRONMENT & GP.HU.410 & $\begin{array}{l}\text { Management of the Water Treatment Station, the equipment and the } \\
\text { environmental conditions }\end{array}$ \\
\hline SECTION 5 & General Procedures & Processes \\
\hline \multirow{4}{*}{$\begin{array}{l}\text { HEALTHCARE SERVICES OF THE } \\
\text { HAEMODIALYSIS UNIT }\end{array}$} & GP.HU.510 & Directives for the implementation of clinical protocols \\
\hline & GP.HU.520 & Directives for the treatment of patients on periodic haemodialysis \\
\hline & GP.HU.530 & $\begin{array}{l}\text { Directives for the hospitalized patients treated for emergency } \\
\text { reasons undergoing haemodialysis }\end{array}$ \\
\hline & GP.HU.540 & Evaluation and monitoring of treatment of patients on haemodialysis \\
\hline
\end{tabular}

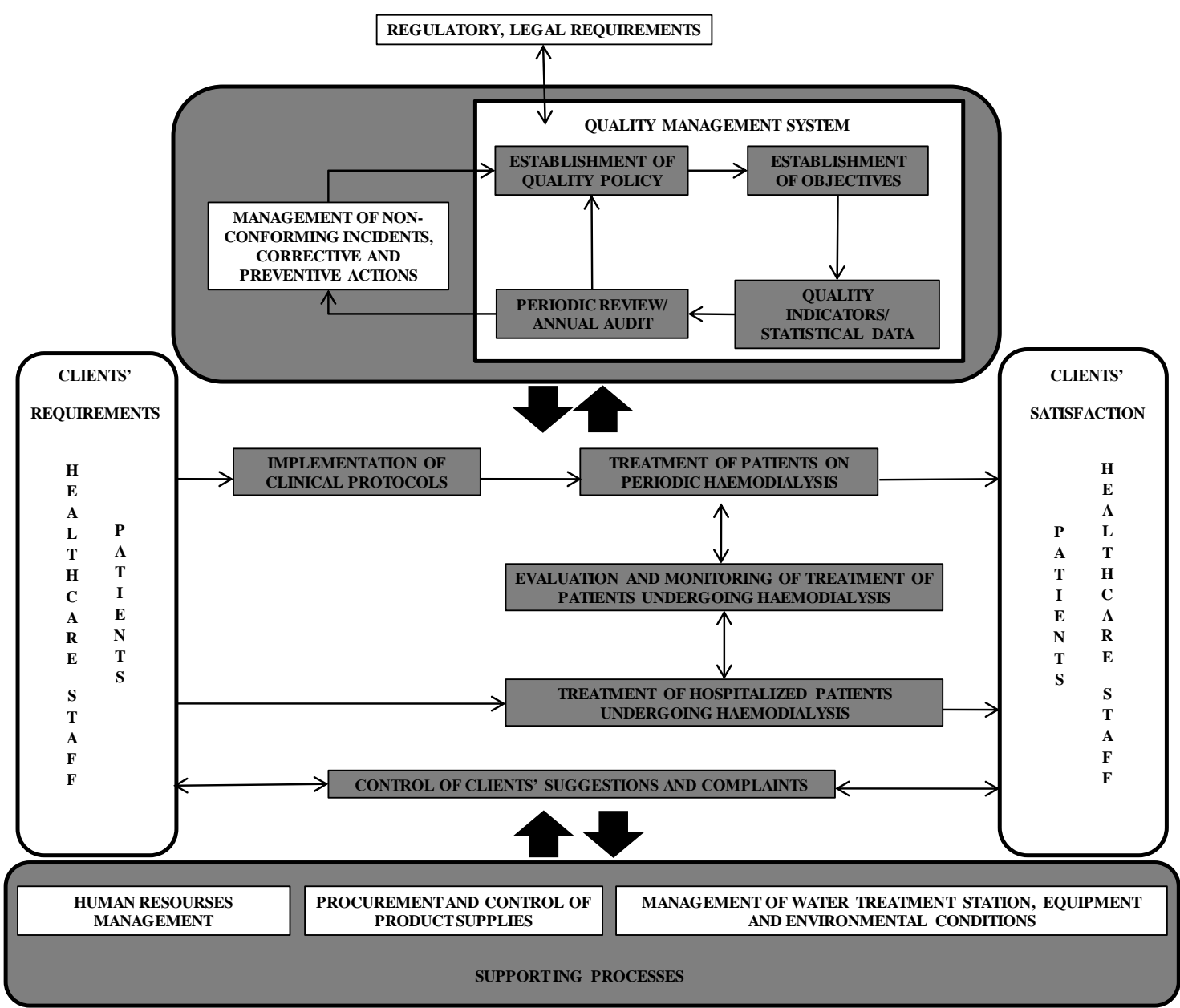

Figure 1. Process Interrelationship Chart that demonstrates the relation of General Procedures of the QMS 
Table 2. Quality Indicators

\begin{tabular}{cl}
\hline SI no. & General categories of Quality Indicators \\
\hline 1 & Number of patients treated \\
2 & Nurse-to-Patient ratio/Doctor-to-Patient ratio \\
3 & Type of vascular access \\
4 & Evaluation of Haemodialysis Quality/Adequacy \\
5 & Evaluation of Medical Treatment \\
6 & Management of Water Treatment Station, Equipment, Environment \\
7 & Incidents of Infections \\
8 & Incidents of non-conforming actions \\
9 & Patients' satisfaction/suggestions \\
10 & Healthcare personnel satisfaction/suggestions \\
11 & Qualifications of personnel/Educational program \\
\hline
\end{tabular}

One of the aforementioned Quality Indicators that are measured is number 9 in Table 2, Patients' satisfaction/suggestions, while the Quality Manual of the QMS stipulated the directive for the Control of the patients' suggestions and complaints, enabling therefore, the identification of the patients' individual needs and the areas of the Haemodialysis Unit's scope of activity that required more attention, further improvement or changes.

During the Annual audit and review, a questionnaire composed of 11 questions was used to evaluate the patients' satisfaction levels, regarding various aspects of the healthcare provided in the Haemodialysis Unit. In Tables 3 and 4 that follow, the demographic characteristics of the patients of the Haemodialysis Unit that participated in this study and their answers to the questions of the questionnaire are demonstrated, respectively.

Table 3. Demographic characteristics of patients

\begin{tabular}{|c|c|c|c|c|c|}
\hline Sl no. & Variables & Categories & Number & Percentage (\%) & Mean \\
\hline \multirow{2}{*}{1} & \multirow{2}{*}{ Gender } & Male & 24 & 68.6 & \\
\hline & & Female & 11 & 31.4 & \\
\hline \multirow{3}{*}{2} & \multirow{3}{*}{ Age } & $45-60 \mathrm{yrs}$. & 8 & 22.9 & \\
\hline & & $61-75$ yrs. & 17 & 48.6 & $69.7 \mathrm{yrs}$. \\
\hline & & $76-88$ yrs. & 10 & 28.6 & \\
\hline \multirow{3}{*}{3} & \multirow{3}{*}{ Marital status } & Single & 2 & 5.7 & \\
\hline & & Married & 25 & 71.4 & \\
\hline & & Divorced/Widowed & 8 & 22.9 & \\
\hline \multirow{2}{*}{4} & \multirow{2}{*}{ Education } & $<9$ yrs. & 28 & 80 & \\
\hline & & $>9$ yrs. & 7 & 20 & \\
\hline \multirow{2}{*}{5} & \multirow{2}{*}{ Occupation } & Working/Pensioners & 32 & 91.4 & \\
\hline & & Not working & 3 & 8.6 & \\
\hline
\end{tabular}

Table 4. Questionnaire

\begin{tabular}{|c|c|c|c|c|}
\hline Sl no. & Questions & Grading Scale & Number & Percentage $(\%)$ \\
\hline \multirow{4}{*}{1} & \multirow{4}{*}{$\begin{array}{c}\text { General satisfaction by Healthcare } \\
\text { provided }\end{array}$} & High & 27 & 77.1 \\
\hline & & Average & 7 & 20 \\
\hline & & Low & 1 & 2.9 \\
\hline & & Not at all & 0 & 0 \\
\hline \multirow{4}{*}{2} & \multirow{4}{*}{$\begin{array}{c}\text { Satisfaction by communication with } \\
\text { Medical staff }\end{array}$} & High & 19 & 54.2 \\
\hline & & Average & 15 & 42.9 \\
\hline & & Low & 1 & 2.9 \\
\hline & & Not at all & 0 & 0 \\
\hline \multirow{4}{*}{3} & \multirow{4}{*}{$\begin{array}{l}\text { Satisfaction regarding future of their } \\
\text { health }\end{array}$} & High & 29 & 82.9 \\
\hline & & Average & 4 & 11.4 \\
\hline & & Low & 2 & 5.7 \\
\hline & & Not at all & 0 & 0 \\
\hline
\end{tabular}




\begin{tabular}{|c|c|c|c|c|}
\hline \multirow{4}{*}{4} & \multirow{4}{*}{$\begin{array}{l}\text { Satisfaction by cordiality of Medical } \\
\text { staff }\end{array}$} & High & 23 & 65.7 \\
\hline & & Average & 12 & 34.3 \\
\hline & & Low & 0 & 0 \\
\hline & & Not at all & 0 & 0 \\
\hline \multirow{4}{*}{5} & \multirow{4}{*}{$\begin{array}{c}\text { Satisfaction by communication with } \\
\text { Nursing staff }\end{array}$} & High & 34 & 97.1 \\
\hline & & Average & 1 & 2.9 \\
\hline & & Low & 0 & 0 \\
\hline & & Not at all & 0 & 0 \\
\hline \multirow{4}{*}{6} & \multirow{4}{*}{$\begin{array}{c}\text { General satisfaction by interest shown } \\
\text { by Healthcare personnel }\end{array}$} & High & 31 & 88.6 \\
\hline & & Average & 4 & 11.4 \\
\hline & & Low & 0 & 0 \\
\hline & & Not at all & 0 & 0 \\
\hline \multirow{4}{*}{7} & \multirow{4}{*}{$\begin{array}{c}\text { Satisfaction by care provided by Medical } \\
\text { staff }\end{array}$} & High & 26 & 74.3 \\
\hline & & Average & 9 & 25.7 \\
\hline & & Low & 0 & 0 \\
\hline & & Not at all & 0 & 0 \\
\hline \multirow{4}{*}{8} & \multirow{4}{*}{$\begin{array}{c}\text { Satisfaction by care provided by Nursing } \\
\text { staff }\end{array}$} & High & 35 & 100 \\
\hline & & Average & 0 & 0 \\
\hline & & Low & 0 & 0 \\
\hline & & Not at all & 0 & 0 \\
\hline \multirow{4}{*}{9} & \multirow{4}{*}{$\begin{array}{l}\text { Satisfaction by quality of services after } \\
\text { QMS implementation }\end{array}$} & High & 34 & 97.1 \\
\hline & & Average & 1 & 2.9 \\
\hline & & Low & 0 & 0 \\
\hline & & Not at all & 0 & 0 \\
\hline \multirow{3}{*}{10} & \multirow{3}{*}{$\begin{array}{l}\text { Belief that certain areas require further } \\
\text { improvement }\end{array}$} & Yes & 2 & 6.1 \\
\hline & & No & 31 & 93.9 \\
\hline & & Did not answer & 2 & - \\
\hline
\end{tabular}

According to the study results, as seen above, $74.3 \%$ of the patients stated that they were highly content by the care provided by the medical staff, but only half, $(54.2 \%)$ found communication with the medical staff and the information they were given by the doctors regarding their current health condition to be adequate and understandable. These results are shown on Figure 2. It is also interesting that $34.3 \%$ of the patients wished that the medical staff of the unit was more cordial and easier to approach, as they felt that the doctors kept them at a distance. All of the patients $(100 \%)$ however, stated that the nursing staff provided high quality nursing care and almost all (97.1\%) felt that the nursing staff was caring, easy to communicate and discuss with, as shown on Figure 3. They observed that the nurses of the Haemodialysis Unit were ready to support them not only regarding the haemodialysis procedure, but also on a more personal level and for practical issues of their everyday life.

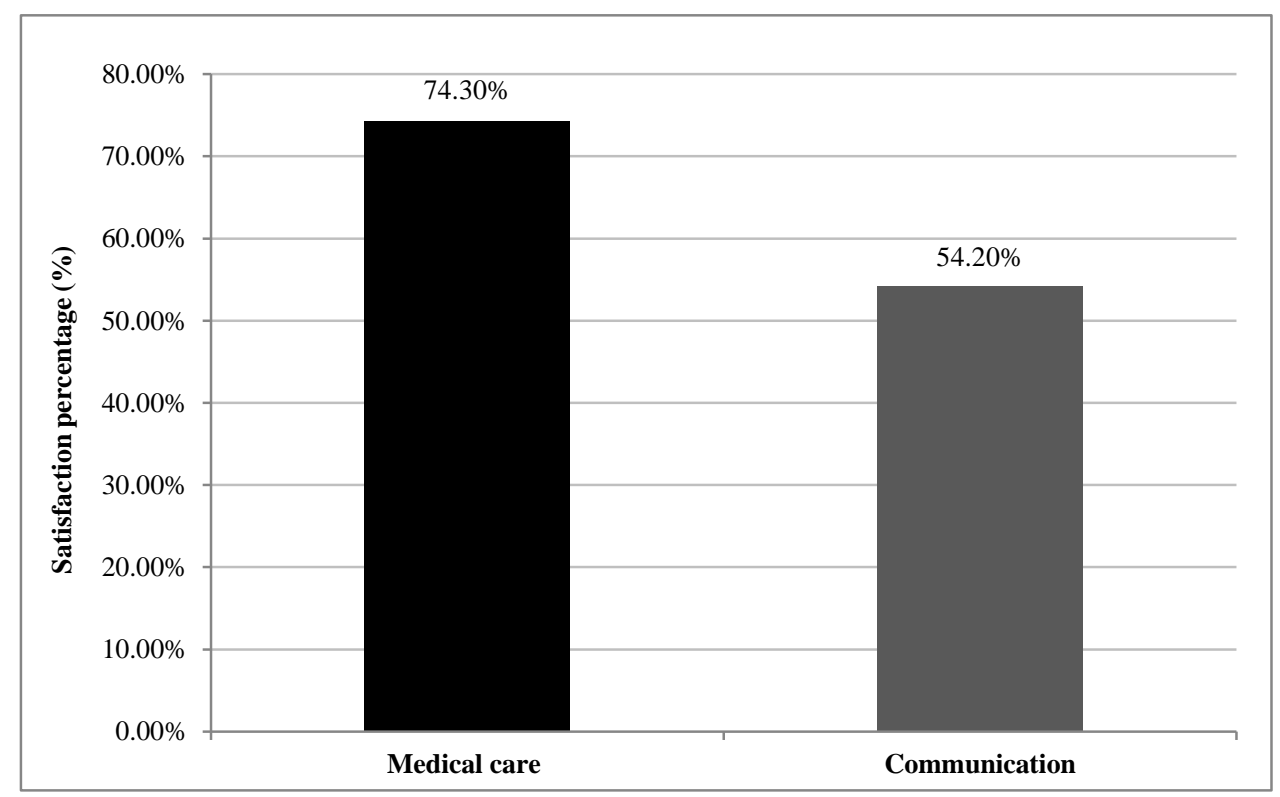

Figure 2. Satisfaction by the Medical staff 


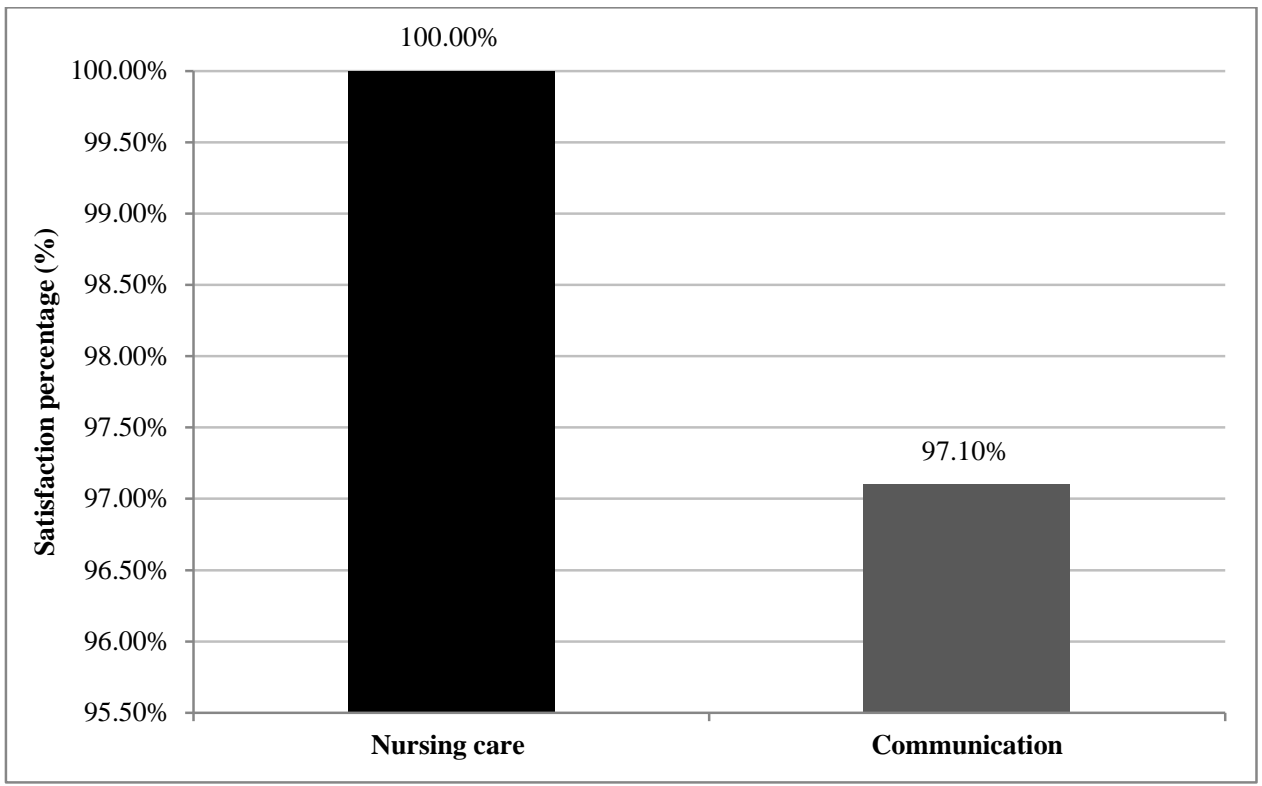

Figure 3. Satisfaction by the Nursing staff

As far as the general levels of satisfaction are concerned, $77.1 \%$ of the patients stated that they were in general highly satisfied by the healthcare provided at the Haemodialysis Unit and $88.6 \%$ were extremely satisfied by the interest shown for their individual needs by the healthcare personnel, as can be seen on Figure 4 . This is mirrored in the high level of security most patients felt regarding the future of their health, $(82.9 \%)$. The patients' high satisfaction levels regarding both the healthcare provided and the services they received from the personnel, is the reason some of them were reluctant to transfer to another Haemodialysis Unit which happened to be closer to their home. This was the case during summer vacation as well, when some of the patients chose to make small one or two day trips and return to the Haemodialysis Unit for treatment, instead of leaving for a longer period of time and receiving haemodialysis treatment at a different Unit.

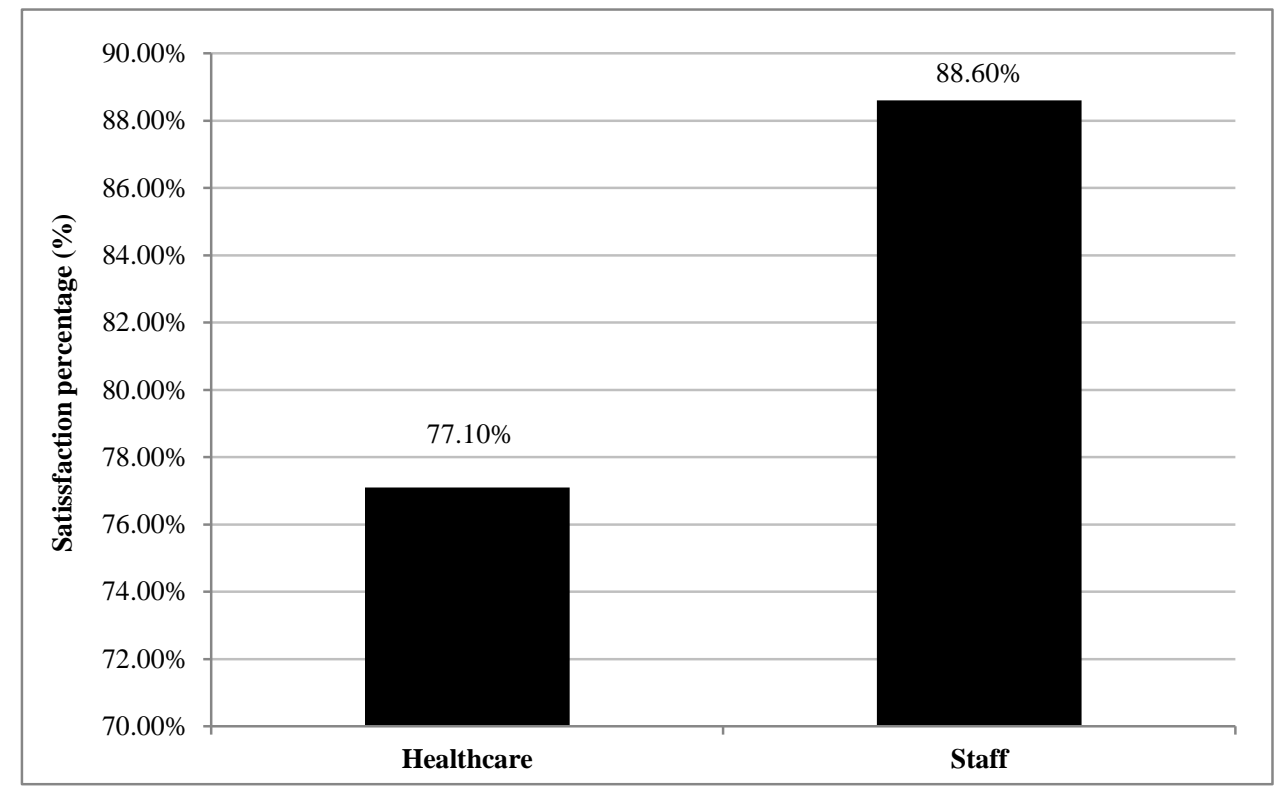

Figure 4. General satisfaction by the services provided

As far as the impact the QMS had made to the patients' satisfaction levels according to their answers, $97.1 \%$ of them stated that the services provided by the Haemodialysis Unit had been improved after the implementation of the QMS and that requests such as the installation of TVs and the permanent collaboration and consultation with a dietologist had been met. Moreover, according to their comments, they felt that their suggestions and complaints were taken into consideration because of the use of the QMS questionnaire and that the Haemodialysis Unit was more reliable since it had received accreditation. It should be noted that the vast majority of the patients were happy to answer the questionnaire and give their comments. They were especially happy to give their praise to the personnel of the Haemodialysis Unit, as they felt much attached to them. Lastly, only $6.1 \%$ of the patients stated that specific areas 
of the services required further improvement. One such example was the variety of the meals provided, which they felt was very limited and could be improved, even taking into account the necessary restrictions. The results mentioned can be seen on Figure 5.

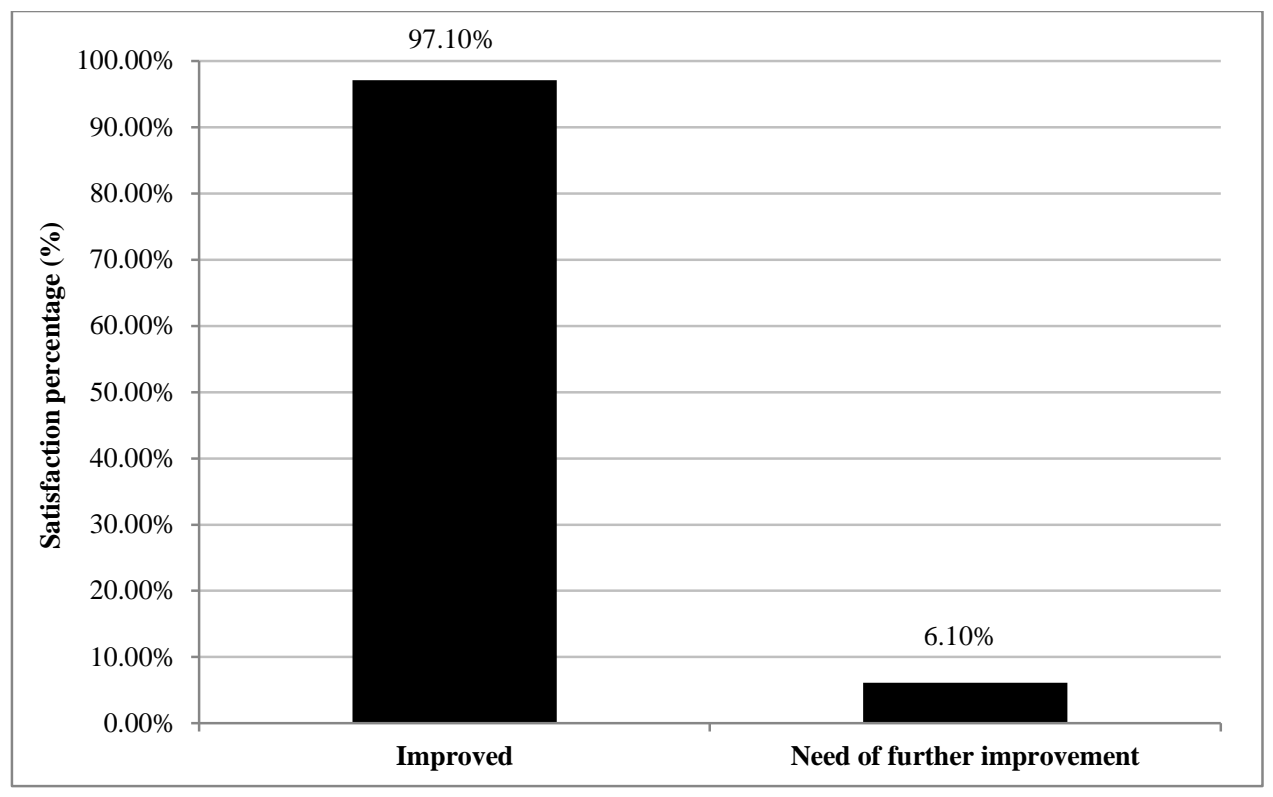

Figure 5. Quality of services after QMS implementation

\section{Discussion}

It is a well-established fact by various studies, that the implementation of a QMS which focuses on continuous improvement, leads to the positive development of procedures and practices in the field of healthcare in general, as well as in other fields [13]. Among other improvements such as compliance with legal requirements, effective monitoring of processes, reduction of deviations and risk, as well as cost, the implementation of a QMS in healthcare and more specifically in a Haemodialysis Unit which is our case, has been proven to lead to continuous improvement of the services provided, in order to consistently meet patients' needs and to evaluate their satisfaction $[11,15]$.

Despite the fact that patients highly value the fulfillment of their personal preferences, it is a reality that in many health-care institutions, assessment of patient satisfaction is not performed routinely [9, 16, 17]. This was also the case in our study, since prior the implementation of the QMS in the Haemodialysis Unit there was no established process used to evaluate patient satisfaction.

According to our study results, $77.1 \%$ of the patients were satisfied in general by the healthcare provided at the Haemodialysis Unit and $88.6 \%$ were satisfied by the interest shown for their individual needs. This is similar to other studies, where patients very rarely evaluated the services provided as "bad" and the level of satisfaction with interpersonal care was high $[16,18]$. In a more recent study, as well, the percentage of the patients satisfied with the care provided at the Haemodialysis Unit was $82.56 \%$, similar to the one found by our research [19].

Moreover, $74.3 \%$ of our sample stated that they were satisfied by the care provided by the medical staff and $100 \%$ by the nursing staff. However, only $54.2 \%$ were satisfied by the information given to them by the doctors of the Haemodialysis Unit, a finding similar to a previous study which indicated that the information dialysis patients receive by the physicians about prognosis is frequently unsatisfactory [9]. In addition, 34.3\% of our patients wished that the medical staff of the Haemodialysis Unit was more approachable, whereas $97.1 \%$ stated that the nursing staff was caring and easy to communicate with. This result is also in accordance to other studies that found patients to be in closer contact with the nursing staff than with physicians in general and during the greater part of the haemodialysis session [16, 20-22]. Furthermore, in a recent study, the majority of the patients observed, that even though they were satisfied with the care they received in general, they weren't satisfied with the amount of time they spent with the doctors of the Haemodialysis Unit [19]. It should be noted as well, that in a previous study, the importance of the satisfactory communication between the patients and the nursing staff, resulted in the active participation of the patients in the decision making process regarding their care [21]. A very important aspect of our study's results was in accordance to this finding, since the patients who participated valued highly having access to information regarding their treatment, because it gave them a sense of security. This outcome is consistent to other studies according to which the patients felt more hopeful towards the future when they participated in the planning of their healthcare [9, 23]. 
The implementation of the QMS had an overall positive impact on the patients' satisfaction level, as $97.1 \%$ of them stated that there was improvement of the services, in accordance to some of their suggestions. The patients felt also, that by answering the questionnaire their opinion about the Haemodialysis Unit was taken into account and similarly to another study, this fact had a positive psychological influence on them and further encouraged them to actively participate in making decisions regarding their healthcare $[1,16]$. The importance of the appraisal of the patients' opinion therefore, which is emphasized by the results of our research, is not a new finding and it has been pursued by the use of different surveys before, aiming at the improvement of the patients' experience regarding the haemodialysis treatment [24].

Lastly, a small percentage of our sample $(6.1 \%)$, requested further improvement in certain areas of the services provided at the Haemodialysis Unit, such as the dietary services, which is an area that received low satisfaction scores in several other studies as well $[16,18]$. The results of our study therefore, which are in accordance to the findings of an older study [16], stated the importance of exploring the patients' opinions as it can lead to improvement of the services provided in the Haemodialysis Unit. Moreover, it can enhance the patients' trust to the personnel of the Haemodialysis Unit, which can result in better communication and consequently in better adherence to the doctors' recommendations by the patients and therefore in an overall more effective treatment [20].

\section{Conclusions}

Patients undergoing chronic haemodialysis experience various restrictions and complications which affect negatively their everyday lives. Hence, the latest developments in renal care aim not only at the patients' survival, but also at the improvement of their quality of life. Haemodialysis Units nowadays, strive to provide to their patients high quality healthcare adapted to their expectations. In order to achieve the desired quality standards and to establish effectiveness and reliability, Haemodialysis Units increasingly opt for the implementation of a Quality Management System.

A Quality Management System when adopted by a Haemodialysis Unit makes use of a questionnaire to evaluate the patients' suggestions and complaints; leading therefore, to the provision of healthcare better adapted to them and to elevated levels of patient contentment due to the better understanding of their individual needs. In addition, the assessment of patient satisfaction results in the better communication between the patients and the unit personnel, promoting the active participation of the patients in the decisions regarding their care, as well as in the better adherence of them to treatment. Moreover, the QMS allows the documentation of the quality of the services provided by the Haemodialysis Unit through evidence based Quality Indicators and leads to a cultural transformation with an emphasis on continuous improvement, which further enhances the patients' trust.

In conclusion, a Quality Management System when implemented in a Haemodialysis Unit can be a useful tool in the hands of healthcare providers in their quest to achieve holistic care for their patients and as a result, it leads to increased patient satisfaction.

\section{Declarations}

\subsection{Author Contributions}

Conceptualization, A.K. and G.G.; methodology, A.K. and G.G.; formal analysis, A.K. and G.G.; writing-original draft preparation, A.K., G.G., E.E. and M.M.; writing-review and editing, A.K.; visualization, A.K.; literature review, A.K., G.G., E.E. and M.M. All authors have read and agreed to the published version of the manuscript.

\subsection{Funding}

The authors received no financial support for the research, authorship, and/or publication of this article.

\subsection{Ethical Approval}

All subjects gave their informed consent for inclusion before they participated in the study. The study was conducted in accordance with the ethical standards of the ELOT EN ISO 9001:2015 Quality Management System established in the Haemodialysis Unit.

\subsection{Data Availability Statement}

The data presented in this study are available in article.

\subsection{Conflict of Interest}

The authors declare that they have no known competing financial interests or personal relationships that could have appeared to influence the work reported in this paper. 


\section{References}

[1] Himmelfarb, J., Vanholder, R., Mehrotra, R., \& Tonelli, M. (2020). The current and future landscape of dialysis. Nature Reviews Nephrology, 16(10), 573-585. doi:10.1038/s41581-020-0315-4.

[2] Jager, K. J., Kovesdy, C., Langham, R., Rosenberg, M., Jha, V., \& Zoccali, C. (2019). A single number for advocacy and communication - worldwide more than 850 million individuals have kidney diseases. Nephrology Dialysis Transplantation, 34(11), 1803-1805. doi:10.1093/ndt/gfz174.

[3] Xie, Y., Bowe, B., Mokdad, A. H., Xian, H., Yan, Y., Li, T., ... Al-Aly, Z. (2018). Analysis of the Global Burden of Disease study highlights the global, regional, and national trends of chronic kidney disease epidemiology from 1990 to 2016 . Kidney International, 94(3), 567-581. doi:10.1016/j.kint.2018.04.011.

[4] Vasiliki, K. S. E., Martha, K. S. N., Evgenia, V. D., \& Georgia, F. B. G. (2009). The impact of chronic heamodialysis on the personality of patients with chronic renal failure. Rostrum of Asclepius2009, 8(3), 240-254.

[5] Murtagh, F. E. M., Addington-Hall, J., \& Higginson, I. J. (2007). The Prevalence of Symptoms in End-Stage Renal Disease: A Systematic Review. Advances in Chronic Kidney Disease, 14(1), 82-99. doi:10.1053/j.ackd.2006.10.001.

[6] Wyld, M., Morton, R. L., Hayen, A., Howard, K., \& Webster, A. C. (2012). A Systematic Review and Meta-Analysis of UtilityBased Quality of Life in Chronic Kidney Disease Treatments. PLoS Medicine, 9(9), e1001307. doi:10.1371/journal.pmed.1001307.

[7] Jansen, D. L., Heijmans, M. J. W. M., Rijken, M., Spreeuwenberg, P., Grootendorst, D. C., Dekker, F. W., ... Groenewegen, P. P. (2012). Illness perceptions and treatment perceptions of patients with chronic kidney disease: Different phases, different perceptions? British Journal of Health Psychology, 18(2), 244-262. doi:10.1111/bjhp.12002.

[8] Kalantar-Zadeh, K., \& Unruh, M. (2005). Health Related Quality of Life in Patients with Chronic Kidney Disease. International Urology and Nephrology, 37(2), 367-378. doi:10.1007/s11255-004-0012-4.

[9] Palmer, S. C., de Berardis, G., Craig, J. C., Tong, A., Tonelli, M., Pellegrini, F., .. Strippoli, G. F. M. (2014). Patient satisfaction with in-centre haemodialysis care: an international survey. BMJ Open, 4(5), e005020. doi:10.1136/bmjopen-2014005020 .

[10] Bayoumi, M., El Guindy, H. A., \& Ahmed, A. (2016). Patients' Satisfaction with Care at Dialysis Unit. International Journal of Nursing Science, 6(5), 117-122.

[11] Lima, G. O., Cruz, R. de F. de A., Vale, S. R. M., \& Carneiro, É. C. R. de L. (2009). Methodology for Implementation of Quality Care in a Dialysis Center. Acta Paulista de Enfermagem, 22(spe1), 580-582. doi:10.1590/s0103-21002009000800028

[12] Materla, T., Cudney, E. A., \& Hopen, D. (2019). Evaluating factors affecting patient satisfaction using the Kano model. International Journal of Health Care Quality Assurance, 32(1), 137-151. doi:10.1108/ijhcqa-02-2018-0056.

[13] Varkey, P., Reller, M. K., \& Resar, R. K. (2007). Basics of Quality Improvement in Health Care. Mayo Clinic Proceedings, 82(6), 735-739. doi:10.4065/82.6.735.

[14] Van der Veer, S. N., van Biesen, W., Couchoud, C., Tomson, C. R. V., \& Jager, K. J. (2013). Measuring the quality of renal care: things to keep in mind when selecting and using quality indicators. Nephrology Dialysis Transplantation, 29(8), 14601467. doi:10.1093/ndt/gft473.

[15] Van den Heuvel, J., Koning, L., Bogers, A. J. J. C., Berg, M., \& van Dijen, M. E. M. (2005). An ISO 9001 quality management system in a hospital. International Journal of Health Care Quality Assurance, 18(5), 361-369. doi:10.1108/09526860510612216.

[16] Donia, A., Elhadedy, M., El-Maghrabi, H., Abbas, M., \& Foda, M. (2015). Exploring the opinion of hemodialysis patients about their dialysis unit. Saudi Journal of Kidney Diseases and Transplantation, 26(1), 73-77. doi:10.4103/1319-2442.148741

[17] Pansini, F., Gargano, L., Sambati, M., Dambrosio, N., D'Altri, C., Giannoccaro, G., ... \& Manno, C. (2007). Patient satisfaction in hemodialysis: a pilot cross-sectional analysis and a review. Giornale italiano di nefrologia: organo ufficiale della Societa italiana di nefrologia, 24(6), 584-594.

[18] Rundle, K., Keegan, O., \& McGee, H. (2004). Patients' experiences of dialysis services: are national health strategy targets being met? Irish Journal of Medical Science, 173(2), 78-81. doi:10.1007/bf02914561.

[19] Iqbal, M. S., Iqbal, Q., Iqbal, S., \& Ashraf, S. (2021). Hemodialysis as long term treatment: Patients satisfaction and its impact on quality of life. Pakistan Journal of Medical Sciences, 37(2). doi:10.12669/pjms.37.2.2747.

[20] Kshirsagar, A. V., Tabriz, A. A., Bang, H., \& Lee, S.-Y. D. (2018). Patient Satisfaction Is Associated With Dialysis Facility Quality and Star Ratings. American Journal of Medical Quality, 34(3), 243-250. doi:10.1177/1062860618796310.

[21] Door, Z. H., \& Mukhtar, H. F. (2019). The Satisfaction of Patients on Maintenance Hemodialysis Concerning the Provided Nursing Care in Hemodialysis Units. IOSR J Nurs Health Sci, 8(06), 25-35. 
[22] Niedźwiecka, A., Nowicki, M., \& Tkaczyk, M. (2009). Chronic dialysis patients' expectations towards dialysis nurses. Polski Merkuriusz Lekarski: Organ Polskiego Towarzystwa Lekarskiego, 26(154), 311-314.

[23] Davison, S. N., \& Simpson, C. (2006). Hope and advance care planning in patients with end stage renal disease: qualitative interview study. BMJ, 333(7574), 886. doi:10.1136/bmj.38965.626250.55

[24] Dad, T., Grobert, M. E., \& Richardson, M. M. (2020). Using Patient Experience Survey Data to Improve In-Center Hemodialysis Care: A Practical Review. American Journal of Kidney Diseases, 76(3), 407-416. doi:10.1053/j.ajkd.2019.12.013. 